\title{
Effect of the method for the elimination of inhibitors present in Miscanthus giganteus hydrolysates on ethanol production effectiveness
}

\author{
Natalia Kordala $^{1,2}$ (D) $\cdot$ Małgorzata Lewandowska $^{1} \cdot$ Włodzimierz Bednarski $^{1}$ \\ Received: 16 October 2020 / Revised: 22 December 2020 / Accepted: 28 December 2020 / Published online: 7 January 2021 \\ (C) The Author(s) 2021
}

\begin{abstract}
The pretreatment of lignocellulosic material performed to improve substrate's susceptibility to enzymatic hydrolysis is usually accompanied by reactions leading to the synthesis of compounds that inhibit the metabolic activity of microorganisms. Their toxicity is the main obstacle to the successful bioconversion of lignocellulosic hydrolysates. The identification of these inhibitors and the choice of the optimal detoxication method are crucial for the improving the efficiency of fermentation processes. Material rinsing with water after processing is a common detoxication practice. However, it generates material losses, thus affecting contents of saccharides in the fermentation medium, which may in turn trigger higher costs of lignocellulose conversion to ethanol and other products with a higher added value. A study was undertaken to determine the effect of selected methods for the detoxication of an enzymatic hydrolysate from Miscanthus giganteus on the fermentation efficiency of saccharide derivatives. The experiment conducted with Mucor rouxii DSM 1191 demonstrated the usability of the detoxication method based on the activated carbon. After 96-h fermentation of Miscanthus hydrolysates, the alcohol content in the post-reaction medium was higher by $14 \%$ than in the control experiment wherein the material was rinsed with water after pretreatment. The experiment carried out with Saccharomyces cerevisiae 7, NRRL 978 showed no positive impact of the alternative detoxication methods replacing material rinsing on the efficiency of ethanol synthesis. The highest concentration of this metabolite $(2.04 \%(v / v))$ was obtained in the experimental variant in which the mentioned operation was coupled with detoxication of hydrolysates using calcium hydroxide.
\end{abstract}

Keywords Lignocellulosic biomass $\cdot$ Alkaline pretreatment $\cdot$ Detoxification $\cdot$ Inhibitory compounds $\cdot$ Biofuels $\cdot$ Ethanol

\section{Introduction}

Considering both the growing demand for the global energy and the non-sustainable supply of fossil fuels, an increasing number of studies have been focused on the development of the so-called green production process of cellulose-derived biofuels $[1,2]$. The improvement of methods for biotechnological conversion of lignocellulosic materials to ethanol

Natalia Kordala

natalia.kordala@uwm.edu.pl

1 Chair of Food Biotechnology, Faculty of Food Sciences, University of Warmia and Mazury in Olsztyn, Heweliusza 1,

10-718 Olsztyn, Poland

2 Chair of Environmental Chemistry, Faculty of Environmental Management and Agriculture, University of Warmia and Mazury in Olsztyn, Pl. Łódzki 4, 10-727 Olsztyn, Poland offers multiple advantages [3]. However, their use on the industrial scale is still curbed due to economic and technical concerns arising from the complexity of a lignocellulosic structure and from the necessity of employing unitary processes which are often very difficult and expensive [4]. For this reason, intense works are in progress to improve production technology of II generation bioethanol [5]. They mainly address the choice of a system and conditions of the process, the selection of microorganisms predisposed for sugar fermentation and enzyme synthesis, and the choice of methods for detoxification of lignocellulosic hydrolysates aimed at removing fermentation inhibitors [6].

The goals of the pretreatment process are to increase cellulose availability for hydrolytic enzymes and to separate major fractions of the lignocellulosic material, however this process is accompanied by reactions that lead to the formation of byproducts derived from lignocellulose which inhibit successive stages of the bioconversion process [7]. The inhibition 
aggravates when the inhibiting substances accumulate due to the recirculation of water used during treatment and also when the substrate is used in high concentrations to boost ethanol concentration. Most of the inhibitors derived from the lignocellulosic complex are formed upon solubilization and degradation of hemicellulose and/or lignin during pretreatment [8]. Inhibiting substances formed during pretreatment include: organic acids (acetic acid, formic acid, and levulinic acid), sugar degradation products like furfural (from xylose) and 5hydroxymethylfurfural (HMF, from hexoses), and lignin degradation products like vanillin, syringaldehyde, and 4hydroxybenzaldehyde $[9,10]$. The composition and concentration of degradation products are dependent on the type (composition) of the lignocellulosic material, chemicals used for pretreatment, and such parameters of this process as: temperature, pressure, incubation time, $\mathrm{pH}$, redox conditions, and catalysts addition $[7,11]$.

Lignin derivatives are the most toxic inhibitors and have been shown to inhibit fermentation of lignocellulosic hydrolysates even at low concentrations [12]. Vanillin or syringaldehyde concentration in the hydrolysate at $1-2 \mathrm{~g}$ $\mathrm{dm}^{-3}$ is sufficient to decrease ethanol yield by $70 \%$ [13] The exact mechanism of their fermentation inhibiting effect remains unknown, however, Zha et al. [14] established it might be based on the discontinuity of a plasma membrane and a resultant decrease in the intensity of cell growth and sugar assimilation.

The highest number of inhibitors are synthesized during acidic pretreatment of lignocellulose [4, 7]. Acidic compounds inhibit enzymatic hydrolysis and contribute to the inactivation of development and/or metabolic activity of most of the genera of alcoholic fermentation yeast [15]. Inhibitors' toxicity is determined by their concentration, species of microorganisms used for fermentation as well as conditions and methods of their culture (e.g. pH, temperature, oxygen content) $[8,10]$.

The effectiveness of lignocellulosic materials bioconversion to bioethanol can be improved via various detoxification treatments conducted with physical, chemical, and biological methods [14]. They can be used after pretreatment and/or after hydrolysis and result in the conversion of hydrolysis and fermentation inhibitors to neutral substances or in their complete removal [16].

The most common physical method of detoxification involves rinsing materials with water after pretreatment which is expected to remove undesirable substances soluble in the liquid phase [17]. It allows increasing the effectiveness of enzymatic saccharification and ethanolic fermentation of hydrolysates. Cantarella et al. [18] demonstrated that poplar tree rinsing with water after pretreatment with the steam explosion method enabled removing inhibitors of water-soluble cellulases and, by this means, increasing the effectiveness of enzymatic hydrolysis of cellulose by $9 \%$ compared to the nondetoxified material.
Physicochemical detoxification of lignocellulosic hydrolysates using activated carbon represents an inexpensive and efficient method based on adsorption of toxic compounds. Its effectiveness is determined by such parameters as: $\mathrm{pH}$, temperature, time, and dose of activated carbon added to the hydrolysate [19].

Among the chemical methods of detoxification, the use of calcium hydroxide in excess (overliming) offers one of the most effective ways for detoxification of acid pretreated materials $[20,21]$ which results in the precipitation of calcium sulfate which adsorbs toxic compounds. This method is, however, time-consuming and expensive [22]. It is also feasible to use other alkaline compounds, like e.g. ammonia water or sodium hydroxide, which may allow producing hydrolysates with a more beneficial composition and higher fermentation degree compared to the overliming treatment [23]. The detoxifying mechanisms of overliming has not been fully elucidated yet. Some scientists suggest the effect of liming to be linked with the precipitation of toxic substances [24], while others that it is due to the chemical transformation of inhibiting compounds which are unstable at high $\mathrm{pH}$ values [22].

This manuscript presents results of a study aimed at improving the effectiveness of Miscanthus giganteus polysaccharides bioconversion to ethanol through the choice of a suitable method for elimination of compounds that inhibit the fermentative activity of selected microorganisms.

\section{Materials and methods}

\subsection{Raw materials}

The experiment was carried out with Miscanthus giganteus, harvested in the autumn of 2013 at the ProductionExperimental Station "Bałcyny" (north-eastern Poland). After drying (ca. 97\% dry matter content), the material was disintegrated (a cutting mill Retsch SM 100) to the fraction size of 1-2 $\mathrm{mm}$. The chemical composition of the native material, including contents of neutral-detergent fiber (NDF), acid-detergent fiber (ADF), and acid-detergent lignin (ADL), was determined using the Fibertec ${ }^{\mathrm{TM}} 1020$ apparatus (FOSS), following the earlier described procedure [25]. Content of the major lignocellulosic fractions - cellulose, hemicellulose, and lignin, in native material biomass were at $45.3 \%$ d.m., $27.1 \%$ d.m. and $9.8 \%$ d.m., respectively.

\subsubsection{Alkaline pretreatment}

The physicochemical pretreatment of Miscanthus giganteus biomass was conducted under the following conditions: temperature, $121^{\circ} \mathrm{C}$; time, $1 \mathrm{~h}$; NaOH addition, $0.1 \mathrm{~g} \cdot \mathrm{g}^{-1}$ substrate d.m.; and solid to liquid fraction ratio, 1:9 [25]. The pretreated biomass was centrifuged at RCF $4100 \mathrm{~g}$ for 
10 min. The supernatant was discarded, whereas the solid fraction was detoxified by rinsing with water and re-centrifugation. Afterward, the solid fraction was filled up with water to the initial sample weight, and the sample acidity was adjusted to $\mathrm{pH} 5.0$ using concentrated phosphoric(V) acid. The resulting reaction medium $\left(200 \mathrm{~cm}^{3}\right.$ portions) was poured into $500 \mathrm{~cm}^{3}$ Erlenmeyer flasks and pasteurized $\left(90^{\circ} \mathrm{C}\right)$.

\subsection{Enzymatic hydrolysis}

The enzymatic hydrolysis of the pretreated material was conducted under conditions established in our previous study [25]. The following enzymatic preparations: cellulase and xylanase from Trichoderma longibrachiatum and cellobiase (Novozyme 188), were added to the earlierprepared reaction media in doses recommended by the producer. The characteristics of the enzymatic preparations is provided in Table 1 . The enzymatic hydrolysis was performed at a temperature of $42{ }^{\circ} \mathrm{C}$ for $72 \mathrm{~h}$, by shaking at $250 \mathrm{rpm}$ (Innova 40 incubator, New Brunswick Scientific). The resulting hydrolysates were determined for the content of reducing sugars using the method with 3,5dinitrosalicylic acid [26].

\subsection{Detoxification of hydrolysates}

The hydrolysates (obtained from the raw material rinsed or not rinsed with water after pretreatment) were fractionated by centrifugation (4100 RCF, $10 \mathrm{~min}$ ). The precipitate was discarded, whereas the supernatant was determined for the content of reducing sugars using the method with 3,5dinitrosalicylic acid (DNS) [26], and then detoxified using the following substances:

a) activated carbon,

b) calcium hydroxide,

c) ammonium hydroxide.

\subsubsection{Treatment with activated charcoal}

The hydrolysates were mixed with activated carbon $(2 \%, w / w)$. The mixture was incubated at a temperature of $25^{\circ} \mathrm{C}$, for $1 \mathrm{~h}$, under stirring at $200 \mathrm{rpm}$. Afterwards, the sample was centrifuged (4100 RCF, $10 \mathrm{~min}$ ), and the supernatant was analyzed for the concentration of reducing sugars [26]. Acidity of thus prepared medium was corrected to $\mathrm{pH} 5.0$ using $85 \%$ orthophosphoric acid, and then the medium $\left(190 \mathrm{~cm}^{3}\right)$ was poured into conical flasks $\left(500 \mathrm{~cm}^{3}\right)$ and pasteurized at $90{ }^{\circ} \mathrm{C} / 20 \mathrm{~min}$.

\subsubsection{Calcium hydroxide overliming}

Acidity of the hydrolysates was adjusted to $\mathrm{pH} 11.0$ using a $20 \%$ solution of calcium hydroxide. Afterwards, they were incubated at a temperature of $45^{\circ} \mathrm{C}$ for $90 \mathrm{~min}$. After completed incubation, $\mathrm{pH}$ value of the hydrolysates was corrected to $\mathrm{pH} 5.0$ using a $95 \%$ solution of sulfuric (VI) acid. In the next stage, the samples were centrifuged (4100 RCF, $10 \mathrm{~min}$ ) to separate calcium sulfate precipitate. All subsequent procedures were as in point 2.3.1.

\subsubsection{Treatment with ammonium hydroxide}

Acidity of the hydrolysates was brought to $\mathrm{pH} 9.0$ using ammonia water ( $25 \%$ solution). Next, they were incubated at $55^{\circ} \mathrm{C}$ for $3 \mathrm{~h}$ under stirring at $200 \mathrm{rpm}$. Afterwards, the liquid was cooled to a temperature of $25{ }^{\circ} \mathrm{C}$ and its acidity was adjusted to $\mathrm{pH} 5.2$. using $95 \%$ sulfuric (VI) acid. All subsequent procedures were as in point 2.3.1.

\subsection{Microorganisms}

Microorganisms used in the study were tested in a previous experiment for their effectiveness in fermenting lignocellulose derivatives [27]. Saccharomyces cerevisiae 7, NRRL 978, originated from the collection of the Department of Industrial and Food Microbiology, Faculty of Food Science, University of Warmia and Mazury in Olsztyn, (Poland). In
Table 1 Enzymes used during researches

\begin{tabular}{llllll}
\hline Enzyme & Microorganisms & Activity & $\mathrm{pH}$ & Recommended dose & Source \\
\hline cellulase & Trichoderma longibrachiatum & $\geq 1000$ & 5.0 & $15 \mathrm{U} \cdot \mathrm{g}^{-1} \mathrm{~d} . \mathrm{m}$. & Sigma Aldrich \\
& & $\mathrm{U}^{1} \cdot \mathrm{g}^{-1}$ & & & \\
xylanase & Trichoderma longibrachiatum & $\geq 1000$ & 5.0 & $15 \mathrm{FXU} \cdot \mathrm{g}^{-1} \mathrm{~d} . \mathrm{m}$. & Sigma Aldrich \\
& & $\mathrm{FXU}^{2} \cdot \mathrm{g}^{-1}$ & & & \\
cellobiase & Aspergillus niger & $\geq 250$ & 4.8 & $30 \mathrm{CBU} \cdot \mathrm{g}^{-1} \mathrm{~d} . \mathrm{m}$. & Sigma Aldrich \\
& & $\mathrm{CBU}^{3} \cdot \mathrm{g}^{-1}$ & & & \\
\hline
\end{tabular}

${ }^{1} \mathrm{U}$ - the quantity of enzyme releasing $1 \mu \mathrm{mol}$ of glucose from cellulose within $1 \mathrm{~h}$ (reaction conditions: $\mathrm{pH}$ 5.0, temperature $37^{\circ} \mathrm{C}$, incubation time $2 \mathrm{~h}$ ); ${ }^{2} \mathrm{FXU}$ the quantity of enzyme releasing $1 \mu \mathrm{mol}$ of xylose from xylan within 1 min (reaction conditions: $\mathrm{pH} 4.5$, temperature $30{ }^{\circ} \mathrm{C}$ ); ${ }^{3} \mathrm{CBU}$ - the quantity of enzyme transforming $1 \mu \mathrm{mol}$ of cellobiose into $2 \mu \mathrm{mol}$ of glucose within $1 \mathrm{~min}$ (reaction conditions: $\mathrm{pH} 4.8$, temperature $50{ }^{\circ} \mathrm{C}$ ) 
turn, Mucor rouxii DSM 1191 (Mucor indicus) strain was obtained from the collection of the Leibniz DSMZ Institute (Germany). They were stored at a temperature of $4{ }^{\circ} \mathrm{C}$ on solid media suitable for a given strain and having the following composition (per $1000 \mathrm{~cm}^{3}$ ):

S. cerevisiae 7: on YPG medium composed of yeast extract, $10 \mathrm{~g}$; glucose, $20 \mathrm{~g}$; peptone, $20 \mathrm{~g}$; and agar, $20 \mathrm{~g}$; having active acidity of $\mathrm{pH} 5.1 \pm 0.1$.

M. rouxii: on $\mathrm{PDA}$ medium with active acidity of $\mathrm{pH} 5.5$ \pm 0.1 , composed of potato extract, $4 \mathrm{~g}$; glucose, $20 \mathrm{~g}$; and agar, $15 \mathrm{~g}$.

\subsection{Preparation of inoculum}

Saccharomyces cerevisiae was cultured on a liquid YPG medium with the composition and acidity as mentioned above (but without agar). In turn, Mucor rouxii was proliferated onto the medium containing (per $1000 \mathrm{~cm}^{3}$ ) glucose, $5 \mathrm{~g}$; yeast extract, $2 \mathrm{~g}$; $\left(\mathrm{NH}_{4}\right) \mathrm{SO}_{4}, 7.5 \mathrm{~g} ; \mathrm{K}_{2} \mathrm{HPO}_{4}, 3.5 \mathrm{~g} ; \mathrm{MgSO}_{4}$. $7 \mathrm{H}_{2} \mathrm{O}, 0.75 \mathrm{~g}$; and $\mathrm{CaCl}_{2} \cdot 2 \mathrm{H}_{2} \mathrm{O}, 1 \mathrm{~g}$; and having active acidity of pH 5.1 \pm 0.1 . Sterile media were inoculated by washing from slant with the proliferated biomass of the respective microorganisms, and incubated in a rotary shaker at $120 \mathrm{rpm}$ and $30{ }^{\circ} \mathrm{C}$ for $24 \mathrm{~h}$. The final cell concentrations in inoculum after incubation were $1.7 \cdot 10^{8} \mathrm{CFU} \cdot \mathrm{ml}^{-1}$ for $S$. cerevisiae 7 and $1.4 \cdot 10^{7} \mathrm{CFU} \cdot \mathrm{ml}^{-1}$ for $M$. rouxii, as confirmed on YPG or PDA medium by the pour plate method.

\subsection{Fermentation of lignocellulose hydrolysates}

The inoculum of $S$. cerevisiae or $M$. rouxii $(5 \%, v / v)$ was added to fermentation worts prepared from Miscanthus giganteus hydrolysates. The fermentation process was performed at $30{ }^{\circ} \mathrm{C}$, under stationary, anaerobic conditions for $72 \mathrm{~h}$ (S. cerevisiae 7$)$ or $96 \mathrm{~h}$ ( $M$. rouxii). The postfermentation medium was determined for the ethanol concentration with the distillation method [28] and for the concentration of residual reducing sugars [26]. [29]:

The yield of fermentation was calculated using the formula

Fermentation yield [\%of theoretical, calculated for fermentable sugars]

$$
=\frac{Y_{\text {fermentation }}}{Y_{\text {glucose }}} \times 100 \%
$$

$\mathrm{Y}_{\text {fermentation }}$ - fermentation yield after 72 or $96 \mathrm{~h}$ of the process $\left[\mathrm{dm}^{3} \mathrm{EtOH} \cdot 100 \mathrm{~kg}^{-1}\right.$ of carbohydrates].

$\mathrm{Y}_{\text {glucose }}$ - theoretical yield based on glucose yield.

\subsection{Analysis of inhibitors in Miscanthus hydrolysates}

Samples of hydrolysates (liquid fraction) were purified using filters that enable separating solid particles in samples intended for HPLC analyses, containing a glass membrane with pore size of $0.4 \mu \mathrm{m}$. Hydrolysates prepared in this way were determined for concentrations of chemical compounds being potential inhibitors of the fermentation process, using the HPLC method: furfural, 5-hydroxymetylfurfural (5HMF), formic acid, levulinic acid, 4-hydroxybenzaldehyde, vanilin. The aforementioned compounds were selected based on findings reported by other authors regarding their inhibiting effect on the fermentation process $[30,31]$ or their putative inhibitory potential [14, 32].

Concentrations of inhibitors were measured by highperformance liquid chromatography (Agilent 1200), using an ion exchange chromatographic column (Benson BP-RA, $100 \mathrm{~mm} \times 7,8 \mathrm{~mm}$, Benson Polymeric lub Rezex ROA $300 \mathrm{~mm} \times 7.8 \mathrm{~mm}$, Phenomenex) as well as RID and DAD detectors. The mobile phase was $0.03 \mathrm{~mol} \cdot \mathrm{dm}^{-3}$ of $\mathrm{H}_{2} \mathrm{SO}_{4}$ with the flow rate of $0.7 \mathrm{~cm}^{3} \cdot \mathrm{min}^{-1}$.

\subsection{Statistical methods}

All experiments were performed in triplicate, and results are expressed as mean. Results obtained were processed using one-way analysis of variance (ANOVA) in STATISTICA software, at a significance level of $p=0.05$.

\section{Results and discussion}

One of the drawbacks of lignocellulose bioconversion, influencing its effectiveness, is the formation of such inhibitors as weak acids and derivatives of phenolics and furan at the stage of plant biomass pretreatment. These compounds suppress activities of hydrolytic enzymes and fermentative microorganisms, thereby inhibiting the bioconversion process and diminishing bioethanol production yield [7, 32]. An appropriately selected method of detoxification used in this process could enable its intensification.

The type of inhibitors formed depends on the type of lignocellulosic material (contents of lignin, cellulose, and hemicellulose) and on the method of its pretreatment. The major groups of inhibitors detected in lignocellulosic hydrolysates included furan derivatives, organic acids, and phenolic compounds [18, 33].

The highest number of inhibitors is synthesized during acidic pretreatment (furfural, 5-hydroxymethylfurfural, formic acid), and the most toxic are lignin derivatives [34]. Even their low concentrations (especially of vanillin and 4hydroxybenzaldehyde) may be lethal to microorganisms. In turn, weaker inhibitors include e.g. acetic acid or levulinic acid [9].

The alkaline pretreatment allows impairing the formation of compounds potent to inhibit hydrolysis and fermentation. This has been proved by results of the chromatographic analysis of hydrolysates prepared from Miscanthus (Table 2). In 
Table 2 Composition of inhibitory compounds in Miscanthus giganteus hydrolysates depending on detoxification method

\begin{tabular}{|c|c|c|c|c|c|c|c|}
\hline Inhibitor $\left(\mathrm{g} \cdot \mathrm{dm}^{-3}\right)$ & $\begin{array}{l}\text { Without } \\
\text { detoxification }\end{array}$ & $\begin{array}{l}\text { Rinsing } \\
\text { with water }\end{array}$ & $\begin{array}{l}\text { Rinsing with water + } \\
\text { activated charcoal }\end{array}$ & $\begin{array}{l}\text { Rinsing with water } \\
+\mathrm{NH}_{4} \mathrm{OH}\end{array}$ & $\begin{array}{l}\text { Rinsing with water } \\
+\mathrm{Ca}(\mathrm{OH})_{2}\end{array}$ & $\begin{array}{l}\text { Activated } \\
\text { charcoal }\end{array}$ & $\mathrm{Ca}(\mathrm{OH})_{2}$ \\
\hline Formic acid & $\mathrm{ND}^{*}$ & ND & 0.358 & 0.328 & 0.336 & 0.97 & 0.773 \\
\hline Levulinic acid & 19.44 & 8.35 & ND & ND & ND & ND & ND \\
\hline 5-hydroxymetylofurfural & ND & ND & ND & ND & ND & ND & ND \\
\hline Furfural & 0.01 & 0.01 & ND & ND & ND & ND & ND \\
\hline 4-hydroxybenzaldehyde & 0.045 & 0.008 & ND & ND & ND & ND & ND \\
\hline Vanillin & ND & ND & ND & ND & ND & ND & ND \\
\hline
\end{tabular}

* ND means not detectable

the present study, furfural concentration in the analyzed samples reached barely $0.01 \mathrm{~g} \cdot \mathrm{dm}^{-3}$, whereas concentrations of the identified lignin derivatives: 4-hydroxybenzaldehyde and levulinic acid, were at $0.045 \mathrm{~g} \cdot \mathrm{dm}^{-3}$ and $19.44 \mathrm{~g} \cdot \mathrm{dm}^{-3}$, respectively. Formic acid, 5-HMF, and vanillin were not detected.

Material rinsing with water after pretreatment contributed to a decrease in concentrations of inhibiting compounds in the hydrolysates compared to their concentrations in the hydrolysates prepared from the non-rinsed material. The concentration of levulinic acid decreased over 2 times and that of 4hydroxybenzaldehyde over 5 times. Other detoxification methods used in research alone or in combination with the rinsing treatment allowed removing all inhibitors, except for formic acid (Table 2). This acid is a product of furfural and 5hydroxymethylfurfural degradation, which explains its presence in the hydrolysates $[9,12,35]$. Its lowest concentration $\left(0.328 \mathrm{~g} \cdot \mathrm{dm}^{-3}\right)$ was determined in the hydrolysate rinsed with water and detoxified with ammonium hydroxide.

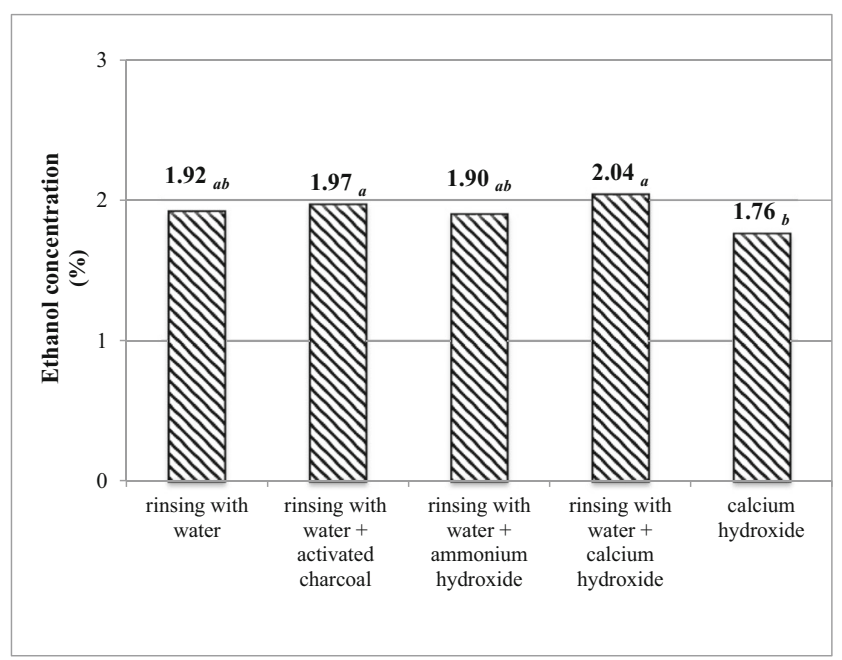

Fig. 1 The final ethanol concentration in Miscanthus giganteus hydrolysates after fermentation with $S$. cerevisiae 7, depending on detoxification method

$\mathrm{a}, \mathrm{b}-$ mean values denoted by the different letters are significantly different at $p=0.05$ (Anova, test HDS Tuckeya).
Especially beneficial is the lack of the most toxic inhibitors, i.e. lignin derivatives.

Miscanthus hydrolysates subjected to various detoxification treatments were used to prepare worts for alcoholic fermentation with Saccharomyces cerevisiae 7 and Mucor rouxii, due to the tolerance of these microorganisms to the inhibiting compounds present in the medium and also due to a high effectiveness of ethanol production they offer. Results achieved in control experiments (with the use of rinsing alone after pretreatment) demonstrated a higher effectiveness of fermentation with $S$. cerevisiae 7 than with $M$. rouxii. (Figs. 1 and 2) - alcohol content in the post-reaction medium was at 1.92 and $1.58 \%(v / v)\left(15.2\right.$ and $12.5 \mathrm{~g} \cdot \mathrm{dm}^{-3}$ ethanol), respectively. The significance of differences was confirmed by results of the statistical analysis.

The best variant of hydrolysates detoxification in the experiment with $S$. cerevisiae 7 turned out to be material rinsing after pretreatment coupled with the overliming treatment (Fig. 1). Fermentation of thus prepared material enabled

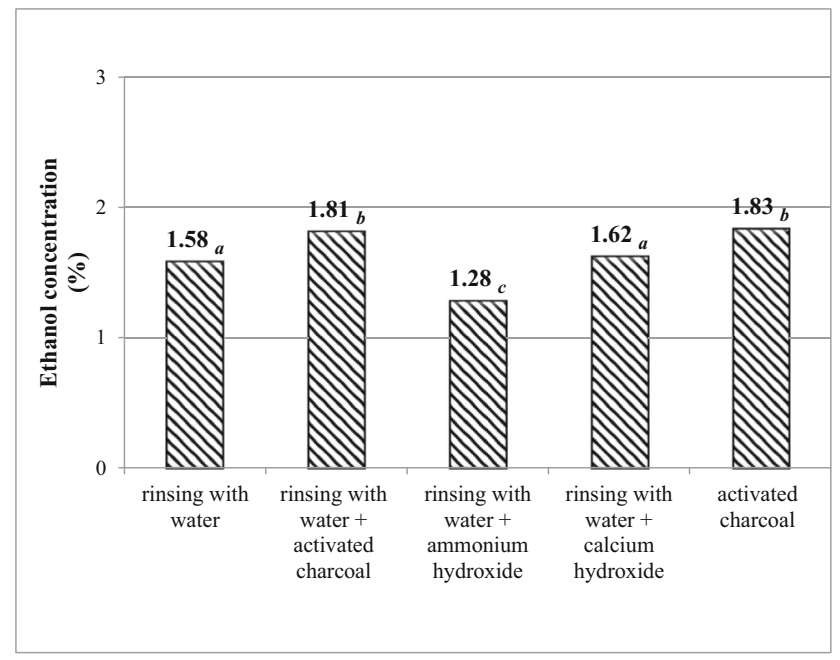

Fig. 2 The final ethanol concentration in Miscanthus giganteus hydrolysates after fermentation with $M$. rouxii, depending on detoxification method

$\mathrm{a}, \mathrm{b}, \mathrm{c}-$ mean values denoted by the different letters are significantly different at $\mathrm{p}=0.05$ (Anova, test HDS Tuckeya). 
alcohol production at $2.04 \%(v / v)$, which corresponded to the total fermentation yield of $51.73 \%$. In the experiment in which material rinsing with water was omitted to check the effectiveness of the method with calcium hydroxide, ethanol concentration was lower and reached $1.76 \%(\mathrm{v} / \mathrm{v})$, which meant fermentation effectiveness decrease by $15 \%$ (44.06\%). Probably, material rinsing with water after alkaline pretreatment is necessary in the fermentation process conducted with this strain of distillery yeast. In turn, in our experiment with rape straw, a higher effectiveness of fermentation with the same strain was achieved for hydrolysates detoxified with activated carbon (unpublished data). It may, therefore, be speculated that the usability of the aforementioned method for elimination of toxic substances is affected by the type of raw material and by the composition of a lignocellulosic complex.

This has been confirmed by contents of inhibiting compounds determined in the hydrolysates from Miscanthus biomass rinsed with water after alkaline pretreatment (Table 2). The hydrolysates were found to contain 4hydroxybenzaldehyde, the lower content of which was obtained in the hydrolysate rinsed with water after pretreatment. In addition, the hydrolysate detoxified only by calcium hydroxide contained formic acid in the concentration 2-fold higher than in the hydrolysate subjected to the coupled detoxification method (rinsing with water + calcium hydroxide treatment). Being a weak acid, it can pervade the cell wall and thereby contribute to the acidification of yeast cytosol. This, in turn, causes the inhibition of many enzymes and significant inhibition of the metabolic process of microorganisms [8].

Taherzadeh and Keikhosro [36] confirmed this dependency and demonstrated that furan compounds and lignin degradation products, being toxic to certain $S$. cerevisiae strains, were removed during the rinsing procedure. These compounds can also be removed upon hydrolysates treatment with calcium hydroxide [37]. The substitution of the rinsing procedure with the above-mentioned detoxification treatment was supposed to bring the same effects, but study results failed to confirm that.

Martín et al. [38] determined also the effect of sugar cane hydrolysate treatment with a $20 \%$ solution of calcium hydroxide on the effectiveness of alcoholic fermentation with the use of $S$. cerevisiae yeast. Alcohol concentration after fermentation of non-detoxified hydrolysates reached $8.8 \mathrm{~g}$. $\mathrm{dm}^{-3}$, but increased by $23 \%$ after the treatment with calcium hydroxide $\left(11.5 \mathrm{~g} \cdot \mathrm{dm}^{-3}\right)$. The total concentration of available sugars determined in both experiments was comparable and reached approx. $33.0 \mathrm{~g} \cdot \mathrm{dm}^{-3}$. Also Cantarella et al. [18] in their study with poplar hydrolysates, confirmed the effectiveness of calcium hydroxide as an inhibitoreliminating substance. The use of water rinsing procedure after pretreatment (explosion of steam having a temperature of $214{ }^{\circ} \mathrm{C}$ ) resulted in ethanol production at $21.5 \mathrm{~g} \cdot \mathrm{dm}^{-3}$ after 24-h fermentation, and process productivity of $0.23 \mathrm{~g}$. $\mathrm{dm}^{-3} \cdot \mathrm{h}^{-1}\left(0.29 \mathrm{~cm}_{\mathrm{A} 100}^{3} \cdot \mathrm{dm}^{-3} \cdot \mathrm{h}^{-1}\right)$. The employment of the overliming method increased process effectiveness and allowed achieving alcohol concentration at $26.5 \mathrm{~g} \cdot \mathrm{dm}^{-3}$ and productivity at $0.37 \mathrm{~g} \cdot \mathrm{dm}^{-3} \cdot \mathrm{h}^{-1}\left(0.47 \mathrm{~cm}_{\mathrm{A} 100}^{3}\right.$. $\left.\mathrm{dm}^{-3} \cdot \mathrm{h}^{-1}\right)$. Results obtained in those experiments are more beneficial that these from our study. This is due to the use of a different lignocellulosic material (poplar) characterized by a different composition, and also by its different pretreatment method (steam explosion).

The present study showed no positive effect of Miscanthus hydrolysates detoxification with ammonia water on the outcomes of their fermentation. The final mean ethanol concentration in post-fermentation worts in the experiments with S. cerevisiae 7 and M. rouxii. Was lower by 1 and $19 \%$, respectively, compared to the control experiment. Opposite results were achieved by Jennings and Schell [39], who reported by $33 \%$ higher ethanol concentration after fermentation of an acidic hydrolysate from maize straw treated with ammonia water, compared to the experiment in which the hydrolysate was detoxified with the overliming method. Contents of furfural and HMF decreased by 90 and $33 \%$, respectively, in the hydrolysates treated with $\mathrm{Ca}(\mathrm{OH})_{2}$ and $\mathrm{NH}_{4} \mathrm{OH}$. The improvement in fermentation effectiveness of worts prepared based on the hydrolysates detoxified with ammonia water was - in authors' opinion - probably due to the removal phenolics and other toxic compounds. Similar results were reported by Alriksson et al. [40], who demonstrated more effective alcoholic fermentation of spruce hydrolysates detoxified with $\mathrm{NH}_{4} \mathrm{OH}$ compared to these treated with $\mathrm{Ca}(\mathrm{OH})_{2}, \mathrm{Mg}(\mathrm{OH})_{2}$, $\mathrm{NaOH}$, and $\mathrm{Ba}(\mathrm{OH})_{2}$. It can, therefore, be concluded that the effectiveness of detoxification procedure is determined by raw material type.

$M$. rouxii has recently been presented as a good candidate for ethanol production from lignocellulosic materials [41]. The hexoses present in the lignocellulosic hydrolyzates can be converted to ethanol by M. indicus with yields and productivity in the same order as S. cerevisiae [42, 43]. Furthermore, $M$. rouxii can assimilate xylose and convert it to ethanol and xylitol [43]. Lennartsson et al. [44] reported that the mostly filamentous and purely yeast-like cells of $M$. indicus were able to tolerate $4.6 \mathrm{~g} \cdot \mathrm{dm}^{-3}$ furfural and $10 \mathrm{~g} \cdot \mathrm{dm}^{-3}$ acetic acid and assimilate the sugars.

In the experiments performed with $M$. rouxii, the most beneficial effects were achieved after hydrolysates detoxification using activated carbon both with and without material rinsing with water (Fig. 2). In the samples rinsed with water and detoxified with the absorbing substance, the final alcohol content in the post-fermentation medium reached $1.81 \%(v / v)$. Analysis of the effectiveness of the method with activated carbon in the experiment in which the rinsing step was omitted brought the expected results as ethanol content in the postreaction medium reached $1.83 \%(\mathrm{v} / \mathrm{v})$ and fermentation effectiveness reached approx. $49 \%$. 
The one-way analysis of variance conducted to compare alcohol concentrations produced depending on the detoxification method of Miscanthus hydrolysates demonstrated statistically significant differences between experimental variants $(p<0.05)$. Therefore, it can be concluded that material rinsing after pretreatment was unnecessary and that the method with activated carbon was effective in removing inhibitors of the fermentative activity of $M$. rouxii.

A research group of Karimi et al. [45] studied the effect of detoxification of hydrolysates from rice straw using calcium hydroxide on the effectiveness of fermentation with $M$. indicus. Upon the use of the above compound as an inhibitor-eliminating agent, alcohol production reached $0.38 \mathrm{~g} \cdot \mathrm{g}^{-1}$, compared to $0.35 \mathrm{~g} \cdot \mathrm{g}^{-1}$ obtained after the fermentation of non-detoxified hydrolysates. Fermentation productivity remained unchanged and reached $0.04 \mathrm{~g} \cdot \mathrm{dm}^{-3} \cdot \mathrm{h}^{-1}$ $\left(0.05 \mathrm{~cm}_{\mathrm{A} 100}^{3} \cdot \mathrm{dm}^{-3} \cdot \mathrm{h}^{-1}\right)$.

A study conducted by Fakhrudin et al. [46] with a hydrolysate from Eucheuma cottonii algae demonstrated that 7.5\% addition of activated carbon and 45-min incubation at a temperature of $40{ }^{\circ} \mathrm{C}$ allowed removing approx. $65 \%$ of HMF, but additionally caused ca. $25 \%$ decrease in reducing sugars content. The same method of toxic substances removal was employed by Mateo et al. [47], who demonstrated that the best variant of inhibitors elimination from hydrolysates of olive wood hydrolysates turned out to be the $2 \%$ addition of activated carbon to the hydrolysate with acidity of $\mathrm{pH} 2$ coupled with its incubation at $30{ }^{\circ} \mathrm{C}$ for $30 \mathrm{~min}$ with shaking at $200 \mathrm{rpm}$. These conditions of detoxification allowed removing approx. $46 \%$ of acetic acid, $81 \%$ of phenolic compounds, and $98 \%$ of furans.

Also combined methods are employed in the search for the most effective methods of inhibitors removal from lignocellulosic hydrolysates. Effects of the coupled use of detoxification with calcium hydroxide and activated carbon were studied by Yadav et al. [48], who subjected rice straw hydrolysates to the aforementioned treatment and then inoculated them with a coculture of $S$. cerevisiae and P. stipitis. After fermentation, alcohol content was at $12.0 \mathrm{~g} \cdot \mathrm{dm}^{-3}$, process yield at $0.4 \mathrm{~g}$. $\mathrm{g}^{-1}$, and process productivity at $0.33 \mathrm{~g} \cdot \mathrm{dm}^{-3} \cdot \mathrm{h}^{-1}(0.48$ $\left.\mathrm{cm}^{3}{ }_{\mathrm{A} 100} \cdot \mathrm{dm}^{-3} \cdot \mathrm{h}^{-1}\right)$.

Nguyen et al. [49] evaluated the usability of various detoxification methods (activated carbon, overliming, ionic exchange with polyethylenimine) in the process of bioethanol production from Gelidium amansii algae. The substrate was acid-treated with $\mathrm{H}_{2} \mathrm{SO}_{4}$ and hydrolyzed $\left(36 \mathrm{~h} ; 45^{\circ} \mathrm{C}\right.$; stirring at $150 \mathrm{rpm}$ ) at an enzyme (Celluclast $1.5 \mathrm{~L}$ ) dose of $16 \mathrm{U}$. $\mathrm{mL}^{-1}$, and the hydrolysate obtained was detoxified. These authors demonstrated $4 \%$ addition of activated carbon to prove best in elimination of hydroxymethylfurfural (reduction of concentration by $89.5 \%$ within $4 \mathrm{~min}$ ). Thus prepared hydrolysate was next subjected to the alcoholic fermentation with S. cerevisiae KCCM 1129 yeast, which resulted in ethanol production at $20.28 \mathrm{~g} \cdot \mathrm{dm}^{-3}$. In the experiment with omitted detoxification step, ethanol concentration in the postreaction medium was lower by $6 \%$. Our study on the effect of detoxification of rape straw hydrolysates with activated carbon or calcium hydroxide on the effectiveness of fermentation of substrate saccharides using $P$. tannophilus KKP 546 yeast did not confirm the usability of any of the methods tested (unpublished data).

As confirmed by results of the performed experiments, the usability of the detoxification methods studied was dependent on genus of the fermenting microorganism. The choice of pretreatment method (which generates the highest number of inhibitors) is driven by the composition of lignocellulosic material, therefore hydrolysates produced with these methods are characterized by different severity of toxicity [50]. This justifies the need for continuation of extensive research with special attention paid to the aforementioned factor.

\section{Conclusion}

When evaluating suitability of detoxification methods, consideration should also be given to their effectiveness and to the extent of substrate weight loss. Among the detoxification procedures compared, the most beneficial effects were achieved upon the use of calcium hydroxide and activated carbon.

The rinsing with water after alkaline pretreatment is an indispensable process enabling the removal of inhibitors of the fermentative activity of $S$. cerevisiae 7 . In turn, detoxification can be omitted at the pretreatment stage (rinsing with water) during fermentation with $M$. rouxii, which allows minimizing weight losses of the material intended for enzymatic hydrolysis.

Acknowledgements This work has been supported by the National (Polish) Centre for Research and Development (NCBiR) as a strategic program: "Advanced Technologies for Energy Generation. Task 4: Development of technology of fuel and energy generation from biomass, agricultural and other wastes"This work has been also carried out with funds for science in years $2010-2013$ as a research project N N312 235838 .

Authors' contributions Not Applicable.

Data availability All the data is present in manuscript itself.

\section{Compliance with ethical standards}

Conflicts of interest/competing interests No competing interest.

Ethics approval Not Applicable.

Consent to participate Not Applicable. 
Consent for publication Authors give their consent for publication upon acceptance of the article.

\section{Code availability Not Applicable.}

Open Access This article is licensed under a Creative Commons Attribution 4.0 International License, which permits use, sharing, adaptation, distribution and reproduction in any medium or format, as long as you give appropriate credit to the original author(s) and the source, provide a link to the Creative Commons licence, and indicate if changes were made. The images or other third party material in this article are included in the article's Creative Commons licence, unless indicated otherwise in a credit line to the material. If material is not included in the article's Creative Commons licence and your intended use is not permitted by statutory regulation or exceeds the permitted use, you will need to obtain permission directly from the copyright holder. To view a copy of this licence, visit http://creativecommons.org/licenses/by/4.0/.

\section{References}

1. Cheng JJ, Timilsina GR (2011) Status and barriers of advanced biofuel technologies: a review. Renew Energy 36:3541-3549. https://doi.org/10.1016/j.renene.2011.04.031

2. Viikari L, Vehmaanperä J, Koivula A (2012) Lignocellulosic ethanol: from science to industry. Biomass Bioenergy 46:13-24. https:// doi.org/10.1016/j.biombioe.2012.05.008

3. Paulova L, Patakova P, Branska B, Rychtera M, Melzoch K (2015) Lignocellulosic ethanol: technology design and its impact on process efficiency. Biotechnol Adv 33:1091-1107. https://doi.org/10. 1016/j.biotechadv.2014.12.002

4. Alvira P, Tomás-Pejó E, Ballesteros M, Negro MJ (2010) Pretreatment technologies for an efficient bioethanol production process based on enzymatic hydrolysis. A review. Bioresour Technol 101:4851-4861. https://doi.org/10.1016/j.biortech.2009. 11.093

5. Pereira SC, Maehara L, Monteiro Machado CM, Sanchez Farinas C (2015) $2 \mathrm{G}$ ethanol from the whole sugarcane lignocellulosic biomass. Biotechnol Biofuels 8:44. https://doi.org/10.1186/s13068015-0224-0

6. Tesfaw A, Assefa F (2014) Current trends in bioethanol production by Saccharomyces cerevisiae: substrate, inhibitor reduction, growth variables, coculture, and immobilization. Int Sch Res Notices 8:111. https://doi.org/10.1155/2014/532852

7. Jönsson LJ, Martín C (2016) Pretreatment of lignocellulose: formation of inhibitory by-products and strategies for minimizing their effects. Bioresour Technol 199:103-112. https://doi.org/10.1016/j. biortech.2015.10.009

8. Behera S, Arora R, Nandhagopal N, Kumar S (2014) Importance of chemical pretreatment for bioconversion of lignocellulosic biomass. Renew Sust Energ Rev 36:91-106. https://doi.org/10.1016/ j.rser.2014.04.047

9. Palmqvist E, Hahn-Hagerdal B (2000) Fermentation of lignocellulosic hydrolysates. II: inhibitors and mechanisms of inhibition. Bioresour Technol 74:25-33. https://doi.org/10.1016/S09608524(99)00161-3

10. van der Pol E, Bakker R, van Zeeland A, Garcia DS, Punt A, Eggink G (2015) Analysis of by-product formation and sugar monomerization in sugarcane bagasse pretreated at pilot plant scale: differences between autohydrolysis, alkaline and acid pretreatment. Bioresour Technol 181:114-123. https://doi.org/10.1016/j. biortech.2015.01.033
11. Jing X, Zhang X, Bao J (2009) Inhibition performance of lignocellulose degradation products on industrial cellulase enzymes during cellulose hydrolysis. Appl Biochem Biotechnol 159:696-707. https://doi.org/10.1007/s12010-009-8525-z

12. Kim D (2018) Physico-chemical conversion of lignocellulose: inhibitor effects and detoxification strategies: a mini review. Molecules 23(2):309. https://doi.org/10.3390/molecules23020309

13. Kim Y, Kreke T, Hendrickson R, Parenti J, Landisch MR (2013) Fractionation of cellulase and fermentation inhibitors from steam pretreated mixed hardwood. Bioresour Technol 135:30-38. https:// doi.org/10.1016/j.biortech.2012.10.130

14. Zha Y, Muilwijk B, Coulier L, Punt PJ (2012) Inhibitory compounds in lignocellulosic biomass hydrolysates during hydrolysate fermentation processes. J Bioproces Biotechniq 2:1-11

15. Hasunuma T, Kondo A (2012) Consolidated bioprocessing and simultaneous saccharification and fermentation of lignocellulose to ethanol with thermotolerant yeast strains. Process Biochem 47(9):1287-1294. https://doi.org/10.1016/j.procbio.2012.05.004

16. Mussatto SI, Roberto IC (2004) Alternatives for detoxification of diluted-acid lignocellulosic hydrolyzates for use in fermentative processes: a review. Bioresour Technol 93:1-10. https://doi.org/ 10.1016/j.biortech.2003.10.005

17. Xie Y, Hu Q, Feng G, Jiang X, Hu J, He M, Hu G, Zhao S, Liang Y, Ruan Z, Peng N (2018) Biodetoxification of phenolic inhibitors from lignocellulose pretreatment using Kurthia huakuii LAM0618T and subsequent lactic acid fermentation. Molecules 23(10):E2626. https://doi.org/10.3390/molecules23102626

18. Cantarella M, Cantarella L, Gallifuoco A, Spera A, Alfani F (2004) Comparison of different detoxification methods for steam-exploded poplar wood as a substrate for the bioproduction of ethanol in SHF and SSF. Process Biochem 39(11):1533-1542. https://doi.org/10. 1016/S0032-9592(03)00285-1

19. Chandel AK, Silva SS, Singh OV (2011) Detoxification of lignocellulosic hydrolysates for improved bioethanol production. In: Dr. Marco Aurelio dos Santos Bernardes (Ed.) biofuel production recent developments and prospects. ISBN: 978-953-307-478-8, InTech

20. De Bari I, Cuna D, Di Matteo V, Liuzzi F (2014) Bioethanol production from steam-pretreated corn Stover through an isomerase mediated process. New Biotechnol 31(2):185-195. https://doi.org/ 10.1016/j.nbt.2013.12.003

21. Kumari R, Pramanik K (2013) Bioethanol production from Ipomoea carnea biomass using a potential hybrid yeast strain. Appl Microbiol Biotechnol 171(3):771-785. https://doi.org/10. 1007/s12010-013-0398-5

22. Millati R, Niklasson C, Taherzadeh MJ (2002) Effect of pH, time and temperature of overliming on detoxification of dilute-acid hydrolyzates for fermentation by Saccharomyces cerevisiae. Process Biochem 38:515-522. https://doi.org/10.1016/S0032-9592(02) 00176-0

23. Jönsson LJ, Alriksson B, Nilvebrant NO (2013) Bioconversion of lignocellulose: inhibitors and detoxification. Biotechnol Biofuels 6: 1-10. https://doi.org/10.1186/1754-6834-6-16

24. Roberto IC, Lacis LS, Barbosa MFS, de Mancilha IM (1991) Utilization of sugar cane bagasse hemicellulosic hydrolysate. Process Biochem 26:15-21. https://doi.org/10.1016/00329592(91)80003-8

25. Świątek K, Lewandowska M, Świątek M, Bednarski W, Brzozowski B (2014) The improvement of enzymatic hydrolysis efficiency of rape straw and Miscanthus giganteus polysaccharides. Bioresour Technol 151:323-331. https://doi.org/10.1016/j. biortech.2013.10.090

26. Miller GL (1959) Use of dinitrosalicylic acid reagent for determination of reducing sugar. Anal Chem 31(3):426-428. https://doi. org/10.1021/ac60147a030 
27. Lewandowska M, Szymańska K, Kordala N, Dąbrowska A, Bednarski W, Juszczuk A (2016) Evaluation of Mucor indicus and Saccharomyces cerevisiae capability to ferment hydrolysates of rape straw and Miscanthus giganteus as affected by the pretreatment method. Bioresour Technol 212:262-270. https://doi.org/10. 1016/j.biortech.2016.04.063

28. AOAC (Association of Official Analytical Chemists) (1990) Official methods of analysis of AOAC (15th ed). AOAC International, Arlington, VA, USA

29. Kłosowski G, Mikulski D (2018) Complementarity of the raw material composition of very high gravity (VHG) mashes as a method to improve efficiency of the alcoholic fermentation process. Process Biochem 74:1-9. https://doi.org/10.1016/j.procbio.2018.08.028

30. Heer D, Sauer U (2008) Identification of furfural as a key toxin in lignocellulosic hydrolysates and evolution of a tolerant yeast strain. Microb Biotechnol 1:497-506. https://doi.org/10.1111/j.17517915.2008.00050.x

31. Huang H, Guo X, Li D. Liu M, Wu J, Ren H (2011) Identification of crucial yeast inhibitors in bio-ethanol and improvement of fermentation at high $\mathrm{pH}$ and high total solids. Bioresour Technol 102: 7486-7493. https://doi.org/10.1016/j.biortech.2011.05.008

32. Klinke HB, Thomsen AB, Ahring BK (2004) Inhibition of ethanolproducing yeast and bacteria by degradation products produced during pre-treatment of biomass. Appl Microbiol Biotechnol 66(1):10-26. https://doi.org/10.1007/s00253-004-1642-2

33. Camesasca L, Ramírez MB, Guigou M, Ferrari MD, Lareo C (2015) Evaluation of dilute acid and alkaline pretreatments, enzymatic hydrolysis and fermentation of napiergrass for fuel ethanol production. Biomass Bioenergy 74:193-201. https://doi.org/10. 1016/j.biombioe.2015.01.017

34. Mitchell VD, Taylor CM, Bauer S (2014) Comprehensive analysis of monomeric phenolics in dilute acid plant hydrolysates. BioEnergy Res 7:654-669. https://doi.org/10.1007/s12155-0139392-6

35. Steinbach D, Kruse A, Sauer J (2017) Pretreatment technologies of lignocellulosic biomass in water in view of furfural and 5hydroxymethylfurfural production- a review. Biomass Conv Bioref 7:247-274. https://doi.org/10.1007/s13399-017-0243-0

36. Taherzadeh MJ, Keikhosro K (2008) Pretreatment of lignocellulosic wastes to improve ethanol and biogas production: a review. Int $\mathrm{J}$ Mol Sci 9:1621-1651. https://doi.org/10.3390/ijms9091621

37. Chandel AK, Kapoor RK, Singh A, Kuhad RC (2007) Detoxification of sugarcane bagasse hydrolysate improves ethanol production by Candida shehatae NCIM 3501. Bioresour Technol 98(10):1947-1950. https://doi.org/10.1016/j.biortech.2006.07.047

38. Martín C, Galbe M, Wahlbom CF, Hahn-Hägerdal B, Jönsson LJ (2002) Ethanol production from enzymatic hydrolysates of sugarcane bagasse using recombinant xylose-utilising Saccharomyces cerevisiae. Enzym Microb Technol 31(3):274-282. https://doi. org/10.1016/S0141-0229(02)00112-6

39. Jennings EW, Schell DJ (2011) Conditioning of dilute-acid pretreated corn Stover hydrolysate liquors by treatment with lime or ammonium hydroxide to improve conversion of sugars to ethanol. Bioresour Technol 102:1240-1245. https://doi.org/10. 1016/j.biortech.2010.08.024

40. Alriksson B, Horváth IS, Sjöde A, Nilvebrant NO, Jönsson LJ (2005) Ammonium hydroxide detoxification of spruce acid hydrolysates. Appl Microbiol Biotechnol 121-124:911-922. https://doi. org/10.1385/ABAB:124:1-3:0911

41. Millati R, Edebo L, Taherzadeh MJ (2005) Performance of Rhizopus, Rhizomucor and Mucor in ethanol production from glucose, xylose, and wood hydrolyzates. Enzym Microb Technol 36: 294-300. https://doi.org/10.1016/j.enzmictec.2004.09.007

42. Abedinifar S, Karimi K, Khanahmadi M, Taherzadeh MJ (2009) Ethanol production by Mucor indicus and Rhizopus oryzae from rice straw by separate hydrolysis and fermentation. Biomass Bioenergy 33:828-833. https://doi.org/10.1016/j.biombioe.2009. 01.003

43. Sues A, Millati R, Edebo L, Taherzadeh MJ (2005) Ethanol production from hexoses, pentoses, and dilute-acid hydrolyzate by Mucor indicus. FEMS Yeast Res 5:669-676. https://doi.org/10. 1016/j.femsyr.2004.10.013

44. Lennartsson PR, Karimi K, Edebo L, Taherzadeh MJ (2009) Effects of different growth forms of Mucor indicus on cultivation on dilute-acid lignocellulosic hydrolyzate, inhibitor tolerance, and cell wall composition. J Biotechnol 143:255-261. https://doi.org/ 10.1016/j.jbiotec.2009.07.011

45. Karimi K, Emtiazi G, Taherzadeh MJ (2006) Production of ethanol and mycelial biomass from rice straw hemicellulose hydrolyzate by Mucor indicus. Process Biochem 41(3):653-658. https://doi.org/ 10.1016/j.procbio.2005.08.014

46. Fakhrudin J, Setyaingsih D, Rahayuningsi M (2014) Bioethanol production from seaweed Eucheuma cottonii by neutralization and detoxification of acidic catalyzed hydrolysate. IJSSD 5(5): 455-458

47. Mateo S, Roberto IC, Sánchez S, Moya AJ (2013) Detoxification of hemicellulosic hydrolyzate from olive tree pruning residue. Ind Crop Prod 49:196-203. https://doi.org/10.1016/j.indcrop.2013.04. 046

48. Yadav KS, Naseeruddin S, Prashanthi GS, Sateesh L, Rao LV (2011) Bioethanol fermentation of concentrated rice straw hydrolysate using co-culture of Saccharomyces cerevisiae and Pichia stipites. Bioresour Technol 102(11):6473-6478. https://doi.org/ 10.1016/j.biortech.2011.03.019

49. Nguyen TH, Sunwoo IY, Jeong GT, Kim SK (2019) Detoxification of hydrolysates of the red seaweed Gelidium amansii for improved bioethanol production. Appl Microbiol Biotechnol 188(4):1-14. https://doi.org/10.1007/s12010-019-02970-x

50. Parawira W, Tekere M (2011) Biotechnological strategies to overcome inhibitors in lignocellulose hydrolysates for ethanol production: review. Crit Rev Biotechnol 31(1):20-31. https://doi.org/10. 3109/07388551003757816

Publisher's Note Springer Nature remains neutral with regard to jurisdictional claims in published maps and institutional affiliations. 